\title{
O MOVIMENTO DE RETORNO AO SUJEITO E A ABORDAGEM DAS REPRESENTAÇÕES SOCIAIS
}

\section{Denise Jodelet*}

\begin{abstract}
Resumo: $\mathrm{O}$ artigo constata, nas ciências sociais, um retorno à noção de sujeito capaz de inspirar uma nova abordagem da subjetividade no campo de estudo das representações sociais. Após um exame dos momentos que significaram a morte e a ressurreição da noção de sujeito, são abordados os principais temas que caracterizaram a sua reintegração na História, na Sociologia e na Antropologia. Esses temas permitem descartar o risco de uma visão solipsista no exame da parte subjetiva das representações sociais. Para esse fim, um esquema tripartite é proposto, relacionando a gênese e as funções das representações sociais a três esferas (subjetiva, intersubjetiva e transubjetiva) e ilustrado por uma análise dos debates relativos ao célebre episódio das caricaturas de Maomé. As reflexões finais propõem que o estudo das representações sociais se oriente para as relações entre pensamento e mudança social.
\end{abstract}

Palavras-chave: representações sociais, sujeito, subjetividade, intersubjetividade, transubjetividade, horizonte, pensamento.

A partir de agora é possível quebrar o silêncio imposto a todas as concepções do sujeito, de suas representações e de suas batalhas.

Alain Touraine (2007, p. 18)

\footnotetext{
Directrice d'études, École des Hautes Études en Sciences Sociales (Laboratoire de Psychologie Sociale, Institut Interdisciplinaire d'Anthropologie du Contemporain). E-mail: denise.jodelet@wanadoo.fr

Texto originalmente publicado em: Connexions, n. 89, p 25-46, 2008 - reproduzido com a autorização dos editores.

Tradução de Lucelena Ferreira.E-mail: lucelena@terra.com.br

Artigo recebido em 31 jul. 2009 e aprovado em 23 out. 2009.
} 
Desde a abertura do campo de estudo das representações coletivas e sociais, a construção teórica destes objetos e o estudo empírico dos fenômenos que lhes correspondem não deixa de levantar uma interrogação sobre sua relação com as representações individuais e sobre o estatuto concedido ao sujeito enunciador e produtor das representações, seja ele individual ou social. Esta questão se encontra expressa, explicitamente ou não, na maneira como a noção de representação social ou coletiva foi elaborada ao longo do tempo, tanto pelo precursor, Durkheim (1895), e pelo iniciador, Moscovici (1961, 1975), deste campo de investigação, como pelos diversos autores atuais e trabalhos que desenvolveram. ${ }^{1}$

Se, para Durkheim, a relação entre representações individuais e coletivas tomou a forma de uma oposição radical, para Moscovici, o fato de tratar a representação social como uma "elaboração psicológica e social" e de abordar sua formação a partir da triangulação "sujeito-outro-objeto"” $\left(1970^{3}, 1984,2000\right)$, conduziu ao questionamento sobre o lugar reservado ao sujeito. Este é tratado mais ou menos explicitamente, nas diferentes abordagens, seja como resposta elementar dos agregados que definem uma estrutura de representação, seja como lugar de expressão de uma posição social, seja como portador de significados circulantes no espaço social ou construídos na interação. Alguns autores preocupamse com a relação entre as representações que são individuais e aquelas que são sociais, chegando a falar em "representações sociais individualizadas", nos limites do caráter social de representações obtidas pela convocação dos conteúdos trazidos pelos indivíduos, ou na necessidade de identificar a maneira como os indivíduos se apropriam das representações socialmente partilhadas. Entretanto, é forçoso reconhecer que a questão do sujeito não é, até o presente, objeto de uma reflexão sistemática na abordagem teórica das representações sociais.

Pode-se atribuir aquilo que, em uma certa medida, parece um vazio teórico a duas razões. Em Psicologia Social, a definição de 
seu objeto próprio conduziu a uma centralização nos fenômenos de interação e de comunicação, localizando o estudo das representações sociais no espaço intermediário tecido pelas relações sociais, arriscando perder de vista a dimensão subjetiva de sua produção. Uma outra razão interveio, a meu ver, de maneira mais decisiva. Diz respeito ao destino que conheceu a noção de "sujeito" nas ciências e na filosofia sociais, particularmente durante a segunda metade do século XX.

Logo depois da Segunda Guerra Mundial, várias correntes de pensamento convergiram para desacreditar a noção de sujeito. Entretanto, as conjunturas históricas e epistemológicas que marcaram o fim do século se traduziram em recolocar em questão paradigmas até então dominantes, tentando uma inversão de posições que a Psicologia Social não podia evitar de levar em conta. Essa inversão associa à reabilitação da noção de sujeito um reconhecimento da noção de representação como fenômeno social maior. O exame deste destino deveria fornecer algumas pistas para avançar na reintegração do sujeito na abordagem teórica das representações sociais.

\section{A morte do sujeito}

Grosso modo, pode-se dizer que a noção de sujeito, associada às idéias de individualismo, de humanismo e de consciência, foi rejeitada sob o golpe de anátemas oriundos do positivismo, do marxismo, do estruturalismo e do pós-modernismo, ou resultantes da combinação de algumas dessas perspectivas. Em primeiro lugar, e desde o século XIX, começou um movimento do qual Nietzsche foi uma figura de destaque, recusando a idéia de que o pensamento é próprio de um sujeito individual e responsável. Esse movimento apoiou-se no conjunto das "teorias da desconfiança", ${ }^{4}$ que denunciaram o caráter ilusório de uma consciência transparente a ela mesma. Mais especificamente, o anátema encontrou duas expressões, 
anulando o sujeito sob a determinação de causalidades objetivantes. Por um lado, em Psicologia, o behaviorismo eliminou o sujeito em razão de sua identificação com a noção de consciência, de caixa preta inacessível à investigação científica. Por outro lado, nas Ciências Sociais, o objetivismo, reificando os processos sociais, reduziu o mundo a um "teatro de marionetes", segundo a imagem de Simmel. $\mathrm{O}$ anátema marxista, enxergando no individualismo o produto de uma ideologia de classe e rejeitando a idéia de uma consciência livre cortada de suas condições materiais, situou o sujeito do lado da falsa consciência. $\mathrm{O}$ anátema estruturalista, responsabilizando o discurso do humanismo, obliterou o sujeito originário e fundamental sob o jogo dos funcionamentos inconscientes de ordens psíquicas, linguística e social. $\mathrm{O}$ anátema pós-moderno, alvejando o sujeito do cartesianismo e seu caráter unitário e substancial, dispersou o Si ("Soi", no original francês) - o self que é uma objetivação da identidade e não um sujeito - sob as "técnicas sociais de saturação", para resgatar uma expressão de Gergen (1991).

Estas condenações subentenderam o que Touraine (2007) chama de "discurso interpretativo dominante", que desloca a pesquisa na direção dos lugares exteriores ao sujeito na análise e interpretação dos fatos sociais e das condutas humanas e sociais, com um efeito sobre os paradigmas de investigação psicológica e social. No campo da Psicologia Social, este movimento de rejeição teve consequências positivas no sentido de reintroduzir a dimensão social na abordagem dos fenômenos estudados. Mas, ao mesmo tempo, isto conduziu à eliminação da idéia de sujeito como entidade psicológica e mental, com a atenção se voltando unicamente sobre os fenômenos de interação, excluindo todo um espaço relacionado com a dinâmica psíquica que subentende a produção do pensamento e da ação e deixando em segundo plano os fenômenos de representação.

Esta orientação ocasionou o esquecimento ou a negligência de certas contribuições que começaram, desde a abertura do campo 
de estudo das representações sociais, a aproximar sua dimensão subjetiva. ${ }^{5}$ Eu penso, entre outras, na contribuição de Kaës (1976), relativa ao aparelho psíquico dos grupos, ou naquela da egoecologia (Zavalloni, 2007), que há trinta anos se dedica, a propósito dos processos identitários, às relações entre representações sociais e subjetividade. Esses pontos de vista remetem a um sujeito que não seria um indivíduo isolado no seu modo de vida, mas seria autenticamente social; um sujeito que interioriza, se apropria das representações ao mesmo tempo em que intervém na sua construção. Seria o momento, quando se observa uma mudança de perspectiva nas ciências humanas, de restabelecer relações com esta tradição. Contanto que os estudos realizados no campo das representações sociais mirem tanto os indivíduos que estão inseridos em e são influenciados pelas redes e contextos sociais quanto os coletivos de natureza diversa (grupos, comunidades, conjuntos definidos por uma categoria social etc.).

Para avançar nesta direção, convém abrir um parêntese sobre as reflexões realizadas, em plano filosófico, sobre a noção de sujeito. Isto por duas razões: por um lado, ressalta-se que as ciências humanas se abriram ao diálogo com a filosofia (Dosse,1995); por outro lado, em Psicologia Social, os críticos da abordagem das representações sociais buscam frequentemente um apoio nos textos filosóficos, tratando particularmente dos fenômenos mentais e discursivos. É obvio que, no escopo deste artigo, não seria o caso de cobrir todas as discussões relativas ao conceito de sujeito. Eu me limitarei, então, a algumas referências que têm relação direta com a articulação da subjetividade e das representações, após um desvio pelo debate sobre a tradição clássica.

\section{Excursus sobre o sujeito cartesiano}

De fato, muitos discursos de recusa do sujeito têm por alvo central um pretenso "sujeito cartesiano" que é associado 
à representação. Essas críticas tiveram um efeito notável sobre a concepção da representação social como modo de conhecimento que liga um sujeito e um objeto, afastando a validade de uma exploração das formas mentais em proveito da discursividade e levantando a questão de relações com as ciências cognitivas. ${ }^{6}$

Ora, com o fim do século XX, algumas vozes se levantaram para esclarecer algumas interpretações equivocadas do dualismo de Descartes, cuja reflexão constituiu, segundo Chomsky (2006, p. 98), a primeira revolução cognitiva que "estimulou fortemente" a segunda revolução cognitiva contemporânea, sob três referências, a saber: o interesse pela natureza da consciência e da lógica que preside a coerência das ações humanas, as teorias do espírito e suas relações com os funcionamentos corporais, o estudo da linguagem marcado pela "confluência de idéias no estilo tradicional esquecido há muito tempo".

Pode-se falar, a propósito das afirmações do pós-modernismo ou da filosofia do espírito, de um "cartesianismo de caricatura" (Jacques, 2000) em razão dos contrassensos operados por certos autores anglo-saxões assimilando o Cogito ao "sentido íntimo", à introspecção que Descartes rejeitava, ou "substancializando" aquilo que era apenas uma proposição existencial pela qual o eu, o mim ["moi", no original francês] se coloca diante de Deus ou do mundo. A limitação da filosofia de Descartes à dualidade almacorpo ou ao dualismo pensamento-entendimento corresponderia a um "uso incerto" das ciências humanas e a uma tradição cultural que conduziram a uma "má leitura" e a "lugares comuns", traduzindo diversas incompreensões ligadas ao desconhecimento de um projeto antropológico fundado sobre a união da alma e do corpo (Milon, 2007). E, de fato, alguns autores apontaram, na articulação do corpo e do ego em Descartes, ${ }^{7}$ as premissas do uso filosófico da noção de carne como pensamento encarnado (Merleau-Ponty, 1964) e do pressuposto fenomenológico de uma intersubjetividade (Husserl, 1950). ${ }^{9}$ 
Para outros, as expressões "sujeito cartesiano" e "subjetividade cartesiana" correspondem a "uma invenção que é um quiproquó" de tradução referido sobretudo em Kant, mas que induz em outros autores, notadamente Heidegger, a erros de interpretação do sentido do Cogito (Balibar; Casin; Libera, 2004). Enfim, encontra-se hoje um filósofo como Zizek (2007) para "reafirmar o sujeito cartesiano" contra o pacto tácito que o esvazia, retomando uma leitura política e psicanalítica do cogito que lhe nega a transparência e mostra sua face obscura.

Por outro lado, insistiu-se na dimensão de reivindicação e de crítica que comporta a posição do $E u$, como o indica Canguilhem (1989, p. 29): “pensar é um exercício do homem que requer a consciência de si na presença no mundo, não como a representação do $E u$, mas como sua reivindicação, pois esta presença é vigilante e mais exatamente de monitoração. [...] O Eu monitorador do mundo das coisas e dos homens é tanto o $E u$ de Spinoza quanto o $E u$ de Descartes. [...] Atribuir à filosofia a tarefa específica de defender o $E u$ como reivindicação inalienável de presença-vigilância é lhe reconhecer somente o papel da crítica".

\section{A emergência da subjetividade}

Esta inscrição ativa no mundo encontra um eco em toda reflexão contemporânea que situa a questão do sujeito em uma perspectiva política e histórica. Esta reflexão interessa sobretudo ao meio intelectual francês, mas ela influenciou o pensamento de correntes contestadoras, particularmente o feminismo do outro lado do Atlântico, aquele de Butler (1997). Isto quer dizer que ela tem implicações importantes para as Ciências Sociais, como resultado da identificação entre a problemática da subjetividade e a da sujeição.

Assim, para Deleuze e Guattari (1980), o sujeito moderno do sistema capitalista é descrito por dois paradigmas: o da servidão, 
que vem do latim servus, a escravização, e o da sujeição, o assujeitamento do indivíduo a regras e objetivações. A saída de um e de outro estado supõe uma liberação na construção da relação consigo mesmo por meio de diversas modalidades práticas. As formas e as figuras da subjetividade são criadas e moldadas, na história, pelas condições sociais e instituições, que Guattari chama de "equipamentos coletivos de subjetivação", que são de ordem religiosa, política, técnica, artística etc. Constatação que deixa aberta uma possibilidade de mudança: a subjetividade permanece hoje massivamente controlada por dispositivos de poder e de saber que colocam as inovações técnicas, científicas e artísticas a serviço das figuras mais retrógradas da sociabilidade. E, no entanto, outras modalidades de produção subjetiva - as processuais e singularizantes - são concebíveis. Estas formas alternativas de reapropriação existencial e de autovalorização podem se tornar amanhã a razão de vida das coletividades humanas e dos indivíduos que se recusam a se abandonar à entropia mortal característica do período que nós atravessamos" (Guattari, 1986, p. 18).

Um movimento semelhante se observa em Foucault, que afirma ter se preocupado sempre com o sujeito, leitmotiv de sua reflexão. Em 1982, definindo o objetivo de seu trabalho ao longo dos últimos vinte anos, ele afirma que "não era analisar os fenômenos de poder nem lançar as bases de uma tal análise. Eu busquei produzir uma história dos diferentes modos de subjetivação do ser humano na nossa cultura" (Foucault, 2001b, p. 1041). Nesta intenção geral se situa o empreendimento de uma história da sexualidade como experiência, entendendo por experiência "a correlação, em uma cultura, entre domínios de saber, tipos de normatividade e formas de subjetividade" (p. 1559). E a tarefa que ele atribui à filosofia é uma emancipação do sujeito: "sem dúvida, o objetivo principal hoje não é descobrir, mas sim recusar aquilo que nós somos. É necessário imaginar e construir aquilo que poderíamos ser para nos 
desvencilharmos daquele tipo de "duplo constrangimento" político que são a individualização e a totalização simultâneas das estruturas de poder moderno". Não se trata de "tentar libertar o indivíduo do Estado e de suas instituições, mas de nos libertarmos nós mesmos do Estado e do tipo de individualização a ele associado. É necessário que promovamos novas formas de subjetividade recusando o tipo de individualidade que nos foi imposto durante muitos séculos (p. 1051).

Foucault situa nos anos 1950 a saída da fascinação hegeliana graças a autores como Bataille, Blanchot, Klossowski, que "ressaltaram o problema do sujeito como problema fundamental para a filosofia e o pensamento moderno", com o abandono da idéia defendida pela filosofia clássica e combatida pelos estruturalistas, segundo a qual o sujeito tem um caráter "fundamental e originário". "O sujeito tem uma gênese, o sujeito tem uma formação, o sujeito tem uma história; o sujeito não é originário" (Foucault, 2001b, p. 590). Em sua busca de um "novo pensamento acerca do sujeito", Foucault tenta assim "explorar aquilo que poderia ser uma genealogia do sujeito, embora sabendo bem que os historiadores preferem a história dos objetos e que os filósofos preferem o sujeito que não tem história. O que não impede de me sentir uma parente empírica daqueles que são chamados de historiadores das "mentalidades" e de uma dívida teórica em relação a um filósofo como Nietzsche que colocou a questão da historicidade do sujeito" (Foucalt, 2001a, p. 506).

Aqueles que se interessam pelas representações sociais só podem ser sensíveis a esta proximidade declarada com a história das mentalidades e não podem, por outro lado, deixar de notar que quando Foucault (2001a) trata especificamente do sujeito, como é o caso no curso "Hermenêutica do sujeito", do Collège de France, ele recorre à noção de representação como "conjunto de idéias". A obra é a única cujo índice comporta o termo representação, que é referido 
dezoito vezes. As passagens onde esse termo é utilizado deixam entrever que a representação intervém no processo de subjetivação como objeto de um trabalho de reflexão e de escolha, no domínio das técnicas do si e do conhecimento do si exercidas na Antiguidade. Além disso, o trabalho sobre as representações se dá sob a orientação de um diretor de consciência, o que remete ao papel que desempenha a interação na elaboração da representação de si.

\section{O retorno do sujeito nas Ciências Sociais}

A ligação entre sujeito historicizado e representações como a correlação de sua transformação vão se reencontrar nos novos paradigmas das Ciências Sociais. O fim das "grandes narrativas", o abandono daquilo que chamamos de "pensamento russo" ou "pensamentochinês"(Rioux; Sirinelli,1997), apósodesmoronamento da empiria soviética e a emergência de um pensamento pós-moderno, ocasionaram, nas Ciências Sociais, perturbações que tiveram por consequência, ao mesmo tempo, a reabilitação do conceito de representação e a afirmação da necessidade de um retorno à idéia de "sujeito ativo e pensante" bem como uma nova interrogação sobre o vínculo social. Segundo Dosse (1995), as ciências humanas, no seu conjunto, "levaram em conta uma concepção que não é mais nem a da divinização do sujeito nem a de sua dissolução". A complexidade crescente dos problemas os conduz a postular "uma forma de indeterminação tornando impossível e vão o confinamento do homem numa lógica exclusivista, seja moral, nacional, genética, neuronal". Por outro lado, esta "nova interrogação sobre o vínculo social implica uma outra escala de análise, mais próxima dos atores sociais. No cotidiano, as representações desempenham o papel de alavancas metodológicas que permitem interessar-se antes pelo instituinte do que pelo instituído" (Dosse, 1995, p. 418).

Assim, a maneira na qual o indivíduo foi conceitualizado na sua relação com a sociedade mudou. A relação indivíduo/sociedade, 
inicialmente formulada em termos de oposição entre ator ou agente e sistema social ou estrutura, evoluiu em um sentido que aproxima, na sua acepção das noções de ator e de agente e os faz juntar-se à noção de sujeito.

Afastando-se de uma concepção de indivíduo orientado por seus interesses e suas intenções privadas, o termo ator tem um uso generalizado nas Ciências Sociais, desde Parsons. Inicialmente, o ator foi considerado como se manifestando por condutas sociais, pessoais e coletivas. Essas refletem as atribuições de papel, de estatuto e dependem de processos de socialização. Elas são definidas por sua conformidade ou seu desvio em relação ao sistema das normas dominantes, em função do qual seu significado é fixado. Esta interpretação colocava em posição de subordinação o ator que desempenha os papéis impostos por um lugar social, sem autonomia diante de uma sociedade regida pelos imperativos do poder e do lucro. A evolução do tratamento da noção de ator colocou, mais tarde, em destaque a possibilidade de escolhas racionais e a capacidade de oposição aos constrangimentos do sistema, aproximando-a daquela de agente, particularmente desenvolvida na tradição inglesa, inspirada por Giddens.

Colocar o indivíduo como agente implica reconhecer neste último um potencial de escolha de suas ações, permitindo-lhe escapar da passividade diante das pressões ou constrangimentos sociais e intervir, de maneira autônoma, no sistema das relações sociais, como detentor de suas decisões e senhor de suas ações. Desenvolvendo a noção de agente, Giddens (1982) denunciou o erro introduzido no pensamento francês pelo estruturalismo, que confundiu uma história sem sujeito transcendental com uma história sem sujeitos humanos conhecedores (knowledgeable) e capazes de exercer uma reflexão sobre sua situação e seu saber. Contra a idéia de uma história sem sujeito (subject-less-history), ele propõe, na sua teoria da estruturação, considerar os seres humanos como agentes 
conhecedores, mesmo se eles agem dentro de limites historicamente especificados que determinam condições sociais que eles não reconhecem e consequências de seus atos que eles não podem prever. Concepção que se aproxima singularmente daquela de sujeito e coloca em primeiro plano a questão dos modos de conhecimento sobre os quais se ancora a ação.

A evolução paralela dos dois termos culmina nas reflexões recentes de Touraine (2007). Ele força a aproximação entre ator e sujeito até produzir uma teoria do sujeito, a fim de integrar as transformações que afetam, devido à globalização, a reflexão de indivíduos e de grupos que marcam uma vontade de liberdade, de afirmação de sua singularidade ou de sua particularidade, e uma reivindicação identitária, um desejo de reconhecimento para si e os outros. Para cercar esta nova realidade que se impõe ao olhar do pesquisador, é necessário “abandonar nossos princípios aparentemente mais garantidos, nossas representações mais clássicas da sociedade e dos atores sociais". A nova demanda social é aquela "do direito a ter direitos"; a idéia de sujeito é convocada pela "transformação de uma consciência de si que se torna mais forte do que a consciência das regras, das normas e das exigências dos sistemas em que se vive e age" (p. 16).

\section{A virada subjetivista na História e na Antropologia}

A mudança de perspectiva se encontra nas outras disciplinas sociais em razão de uma crise que se situa a partir dos anos 1980. De um ponto de vista epistemológico, esta crise decorre tanto da consideração dos determinismos econômicos e dos condicionamentos sociais como da recusa do modelo positivista ou do caráter dogmático da virada linguística. Disto resultou, nas contribuições correspondentes à chegada do terceiro milênio, o destaque da historicidade, do pragmatismo e dos modelos interpretativos se oferecendo "a uma 
apropriação desligada do oposto das transposições mecânicas, por aplicação, do 'pensamento pronto para pensar'10 dos esquemas teóricos ossificados" (Lepetit, 1995, p. 15).

Este movimento desembocou, particularmente em História, sobre uma dupla perspectiva. Por um lado, um recurso sistemático à noção de representação, como dizia Boreau (1995, p. 20): “A noção de representação, depois de quinze anos, se implantou fortemente no ateliê do historiador. Este sucesso não é um modismo, já que está ligado a um verdadeiro progresso na descrição dos estados mentais e de sua expressão segundo sua ligação com o processo histórico ou social". Por outro lado, a emergência de uma corrente de crítica própria ao campo histórico. ${ }^{11}$ Em conseqüência das perspectivas abertas, a Antropologia e a micro-história ${ }^{12}$ forneceram aos historiadores as razões de uma mudança de escala na abordagem e na definição dos objetos de estudo. Elas preconizaram o respeito à complexidade dos fenômenos estudados, a reabilitação da experiência dos atores sociais, considerados na sua singularidade e sublinhando a importância do contexto particular que dá sentido à experiência.

Sobre o plano coletivo, isto levou a considerar o papel dos sujeitos tidos por "pensantes e que agem" e a reconhecer a importância das reivindicações identitárias nas lutas pela dominação e reconhecimento social. O estudo dessas lutas que envolvem a estruturação do social acentua as "estratégias simbólicas que determinam posições e relações e constroem, para cada classe, grupo ou meio, uma percepção de si constitutiva da sua identidade" (Chartier, 1989). Tais afirmações apresentam uma singular aproximação com a ótica psicossocial, já que ela desloca o centro de gravidade do indivíduo que manifesta sua pertença grupal para a afirmação identitária de uma coletividade por meio de processos simbólicos que regem as relações sociais.

Pode-se, assim, falar de um novo paradigma, o "paradigma subjetivista", para utilizar uma expressão de Noiriel (1989). Este 
último, evocando para a Sociologia a possibilidade de contribuir com a superação dos impasses da história quantitativa, propõe que se recorra a noções como a da experiência vivida e de significados investidos pelos indivíduos em suas condutas, por um lado, e, por outro, as da objetivação sob a forma de evidência cotidiana e de interiorização referente ao processo pelo qual as normas e valores sociais são integrados no espaço interior dos indivíduos.

Em Antropologia, a integração das contribuições da psicanálise e das ciências cognitivas em autores como Godelier (2007) e Descola (2006) orientou a atenção em direção aos processos psíquicos e cognitivos que participam das organizações sociais e estruturam a formação das identidades dos sujeitos sociais inscritos em uma ordem simbólica e política. Assim, Godelier, reconstruindo "o nascimento de si do sujeito social", insiste no fato de que, por meio da linguagem, "os outros estão nele e com ele", e que, por meio das interações, ele interioriza a visão cultural de seu eu. "A presença ideal e emocional nos indivíduos de relações sociais que caracterizam sua sociedade constitui a parte subjetiva destas relações sociais, um conjunto de representações e de valores que estão presentes tanto no indivíduo quanto nas suas relações com outros, já que eles dão significado a suas relações. Desta forma, vemos que as relações sociais não existem somente entre os indivíduos, elas estão igualmente neles - sob diversas formas" (p. 179). Descola lança a hipótese de que a maneira de estruturar a experiência do mundo e do outro nas diferentes culturas e épocas é regida por processos cognitivos. Ela ocorre em duas modalidades operadas e assumidas por todos os membros de um coletivo: por um lado, a identificação pela qual são colocadas as diferenças e semelhanças entre si e os outros - humanos e não humanos - com base na imputação de uma interioridade (estado de consciência, alma etc.) e de uma fisicalidade (materialidade, corporeidade); por outro lado, a relação definidora dos laços estabelecidos entre os existentes, baseados seja em sua equivalência - a troca, o dom -, seja sobre sua dependência - a 
produção, a proteção, a transmissão. Essa caracterização a partir de um funcionamento cognitivo que remete a uma interioridade, senão a uma subjetividade, permite estabelecer modelos de organização de relações sociais que poderiam ser aplicados ao estudo das representações sociais em espaços sociais definidos.

\section{As representações sociais e o sujeito}

Todas estas evoluções ocorridas nas ciências sociais deveriam incitar os psicólogos sociais que tratam de representações a aprofundar os meios de análise de tudo que diz respeito à subjetividade. Reconhecer a existência de um sujeito não implica supor nele um estado de solipsismo. Os modelos de interiorização dos quais o parâmetro é o habitus de Bourdieu, o da psicanálise e as diferentes concepções sociais da relação com o outro (Jodelet, 2003) interiorizam o outro no sujeito. Em Psicologia Social, Zavalloni (2007) mostra a parte que se refere à representação da alteridade na estruturação de uma identidade que envolve também a corporeidade. Mais recentemente, Markova (2007), inspirada por Bakhtin, remete à dialogicidade tanto a formação das categorias de pensamento como a das representações, numa retomada ontológica da oposição distintiva emprestada da Antropologia. ${ }^{13}$ Entretanto, a necessidade de afastar uma visão solipsista do sujeito não implica de modo algum em relacionar os sistemas de pensamento a uma pura estruturação pela troca linguageira ("langagier", no original em francês). O lugar do encontro intersubjetivo está, como mostra Merleau-Ponty (2003), no campo da instituição que significa "estabelecimento em uma experiência (ou em um aparelho construído) de dimensões (no senso comum, cartesiano: sistema de referências) em relação às quais toda uma séria de outras experiências terão sentido e constituirão uma sequência, uma história". O sujeito como outro é inseparavelmente instituído e instituidor: "Eu me projeto nele e ele em mim, há uma projeção-introjeção, produto do que eu faço nele e do que ele faz 
em mim, verdadeira comunicação através de um movimento lateral: trata-se de um campo intersubjetivo ou simbólico, o dos objetos culturais, que é nosso meio, nossa articulação, nossa junção" (p. 3538).

O que parece importante para o futuro é estudar de que maneira um trabalho sobre representações pode, ao mesmo tempo, tirar partido e contribuir para um trabalho sobre a subjetivação, de um duplo ponto de vista teórico e prático. A visão geral, certamente limitada, que acaba de ser traçada, poderia, considerando a ligação entre subjetividade e representação, fornecer certas orientações sobre o plano da produção de conhecimentos e significações, dos efeitos sobre os conteúdos representacionais imputados às formas de subjetivação ligadas aos quadros sociais e históricos ou do papel das representações na constituição das subjetividades e de sua afirmação identitária.

Sob este ponto de vista, seria interessante ver como a intervenção sobre as representações endossadas por eles poderia contribuir para uma mudança de subjetividade. Esta perspectiva não é nova. Foucault a abordou a propósito das técnicas do eu. Sobre o plano empírico, é suficiente recorrer aos diferentes modelos propostos pela intervenção social tanto em Sociologia como em Psicossociologia (Jodelet, 2007b). Para induzir a uma mudança, seja por meio de modos de influência ou de processos de interação e de negociação de significado em vista de uma ressignificação da experiência dos atores sociais, esses modelos de intervenção fazem sempre referência a um trabalho sobre as representações, individuais, sociais ou coletivas. Esse trabalho supõe a correção de crenças consideradas como inadequadas ou falsas, a valorização de saberes do senso comum, a conscientização crítica das posturas ideológicas, a reinterpretação das situações de vida, a colocação em perspectiva das posições em função de uma análise dos contextos de ação e do ponto de vista dos atores. Estas perspectivas implicam 
que a abordagem de representações sociais pode fornecer, para uma mudança social ao nível individual ou coletivo e qualquer que seja o domínio de intervenção, a melhor contribuição, mas também a mais difícil. A melhor, porque os modos que os sujeitos possuem de ver, pensar, conhecer, sentir e interpretar seu modo de vida e seu estar no mundo têm um papel indiscutível na orientação e na reorientação das práticas. A mais difícil, pois as representações sociais são fenômenos complexos, incitando um jogo de numerosas dimensões que devem ser integradas em uma mesma apreensão e sobre as quais é necessário intervir conjuntamente. A este respeito, eu proponho um quadro analítico que permita situar o estudo da representação social no jogo da subjetividade.

\section{As três esferas de pertença das representações sociais}

Para analisar as representações sociais produzidas pelos indivíduos e os grupos localizados em espaços concretos da vida e, ultrapassando o estágio da simples descrição de estados representacionais, definir as modalidades de uma ação transformadora, eu proponho o esquema seguinte, que delimita as esferas ou universos de pertença das representações.

\section{As esferas de pertença das representações sociais}

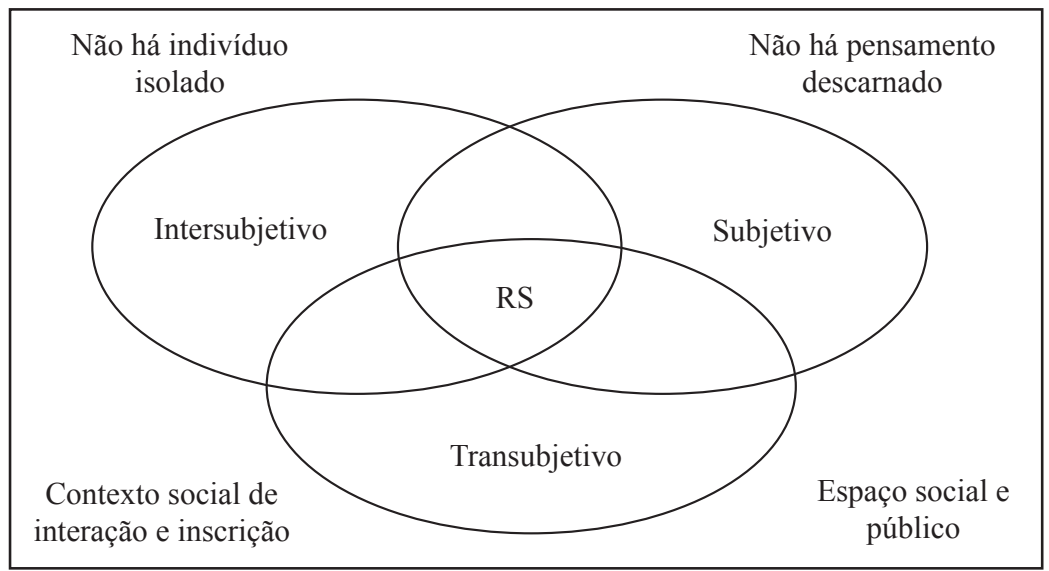


Em se tratando de sua gênese e de suas funções, as representações sociais podem ser relacionadas a três esferas de pertença: a da subjetividade, a da intersubjetividade e a da transubjetividade. De acordo com a teoria das representações sociais (Moscovici, 1961, 1976; Jodelet, 1989), toda representação social é relacionada a um objeto e a um sujeito. Ainda que devamos sempre levar em consideração o tipo do objeto referido no estudo de uma representação social, o comentário do esquema será focalizado, por razões analíticas, exclusivamente sobre o sujeito pensante. Vale sublinhar, como é indicado nos ângulos do esquema, que os sujeitos devem ser concebidos não como indivíduos isolados, mas como atores sociais ativos, afetados por diferentes aspectos da vida cotidiana, que se desenvolve em um contexto social de interação e de inscrição. A noção de inscrição compreende dois tipos de processos cuja importância é variável segundo a natureza dos objetos e dos contextos considerados. Por um lado, a participação em uma rede de interações com os outros, por meio da comunicação social - aqui eu me refiro ao modelo da triangulação sujeito-outro-objeto proposto por Moscovici (1984). Por outro lado, a pertença social definida em vários níveis: o do lugar na estrutura social e da posição nas relações sociais, o da inserção nos grupos sociais e culturais que definem a identidade, o do contexto da vida onde se desenrolam as interações sociais, o do espaço social e público.

A noção de subjetividade nos conduz a considerar os processos que operam no nível dos indivíduos eles-mesmos. Ainda que nossas pesquisas visem a deduzir os elementos representacionais partilhados, seria reducionista eliminar de nosso exame aquilo que corresponde aos processos pelos quais o sujeito se apropria e constrói suas representações. Esses processos podem ser de natureza cognitiva, emocional, e dependem de uma experiência de vida (Jodelet, 2006). Eles remetem igualmente aos estados de sujeição ou de resistência de que falamos acima. Deste ponto de vista, convém distinguir as representações que o sujeito elabora ativamente daquelas que ele 
integra passivamente, no contexto das rotinas de vida ou sob a pressão da tradição ou da influência social. Vale ainda ressaltar que o sujeito se situa no mundo, em primeiro lugar, por seu corpo, como estabelece a fenomenologia. A participação no mundo e na subjetividade passa pelo corpo: não há pensamento desencarnado, flutuando no ar. Isso nos conduz a integrar na análise das representações os fatores emocionais e identitários, ao lado das tomadas de posição ligadas ao lugar social (Doise, 1990) e das conotações que vão caracterizar, em função da pertença social, a estrutura das representações (Abric, 1994). As diversas facetas que qualificam o sujeito não entram em jogo de maneira sistemática na produção das representações sociais e sua importância relativa deve evidentemente ser relacionada ao tipo de objeto representado e à situação na qual se forja a representação. Levar em consideração o nível subjetivo permite compreender uma função importante das representações. As representações, que são sempre de alguém, têm uma função expressiva. Seu estudo permite acessar os significados que os sujeitos, individuais ou coletivos, atribuem a um objeto localizado no seu meio social e material, e examinar como os significados são articulados à sua sensibilidade, seus interesses, seus desejos, suas emoções e ao funcionamento cognitivo.

A esfera de intersubjetividade remete às situações que, em um dado contexto, contribuem para o estabelecimento de representações elaboradas na interação entre os sujeitos, apontando em particular as elaborações negociadas e estabelecidas em comum pela comunicação verbal direta. São numerosos os casos que ilustram o papel da troca dialógica de que resultam a transmissão de informação, a construção de saber, a expressão de acordos ou de divergências a propósito de objetos de interesse comum, a interpretação de temas pertinentes para a vida dos participantes em interação, a possibilidade de criação de significações ou de ressignificações consensuais. Esse tipo de troca é objeto privilegiado da Psicologia Social e das intervenções de tipo terapêutico ou daquelas que são destinadas a indivíduos que 
desejam modificar sua relação com uma situação de vida em um contexto comunitário, ou de trabalho em um contexto organizacional. Nesses espaços de interlocução, recorre-se, também, a um universo já constituído, no plano pessoal ou social, de representações. Estas intervêm como meio de compreensão, ferramentas de interpretação e de construção de significações partilhadas em torno de um objeto de interesse comum ou de acordo negociado.

Finalmente, a terceira esfera, a da transubjetividade, foi menos levada em consideração, ao menos no decorrer dos últimos anos. Ela se compõe de elementos que atravessam o nível tanto subjetivo quanto intersubjetivo. Sua escala domina tanto os indivíduos e os grupos quanto os contextos de interação, as produções discursivas e as trocas verbais. O emprego da noção de transubjetividade, presente na fenomenologia, é aqui diretamente tributário da reflexão de R. Boudon (1995) sobre "a racionalidade subjetiva" e as "razões transubjetivamente válidas" de endossar uma crença indexada em uma situação (quadro espaço-temporal, campo social ou institucional, universo de discurso) ou derivada de um "entrelaçamento de princípios, evidências empíricas, lógicas ou morais" e de partilhá-la coletivamente porque ela faz sentido para os atores implicados.

$\mathrm{Na}$ formação das representações sociais, a esfera da transubjetividade se situa diante da intersubjetividade e remete a tudo que é comum aos membros de um mesmo coletivo. Este aspecto comunitário pode ter, efetivamente, várias origens. Ele pode resultar do acesso ao patrimônio de recursos fornecidos, para a interpretação do mundo, pelo aparelho cultural. Este oferece os critérios de codificação e de classificação da realidade, os instrumentos mentais, os repertórios que servem para construir as significações partilhadas e constitui o pano de fundo que permite a intercompreensão (Searle, 1979). Ele pode depender do jogo de constrangimentos ou de pressões ligadas seja às condições materiais de existência, seja às imposições da estrutura das relações sociais e de poder, seja aos 
sistemas de normas e valores, seja ao estado de mentalidades que os historiadores tratam como sistemas de representações que orientam as práticas coletivas e garantem o laço social e a identidade coletiva. Ele remete igualmente ao espaço social e público onde circulam as representações provenientes de fontes diversas: a difusão pelos meios de comunicação de massa, os contextos impostos pelos funcionamentos institucionais, as hegemonias ideológicas etc. Atravessando os espaços de vida locais, esta esfera constitui um meio onde mergulham os indivíduos. Pela sua circulação, as representações assim geradas ultrapassam o quadro das interações e são endossadas, sob a forma de adesão ou de submissão, pelos sujeitos. Para dar um exemplo do funcionamento desta esfera, citarei o caso do jogo de representações na compreensão de um acontecimento político.

\section{A compreensão dos acontecimentos}

As tendências recentes de interpretação da ação nas ciências sociais acentuam a importância do acontecimento, evento inesperado em uma ordem temporal e um estado de coisas. Duas direções são seguidas quando se trata de dar significado a um acontecimento. Para a ciência, são as consequências do acontecimento que permitem analisar suas significações e seu alcance. Para o senso comum, estas últimas decorrem da ancoragem do acontecimento no sistema de pensamento preexistente das pessoas que o interpretam. Segundo os pertencimentos sociais, os engajamentos ideológicos, os sistemas de valores referenciais etc., um mesmo acontecimento pode mobilizar representações transubjetivas diferentes, que o situam em horizontes variáveis. Decorrem dos sujeitos interpretações que se constituem em objeto de debate e podem levar a situações de consenso ou de dissenso.

A noção de horizonte, emprestada da fenomenologia, designa aqui os domínios segundo os quais um mesmo objeto pode ser 
situado. O objeto que um sujeito observa pode ser considerado em horizontes diferentes. Por exemplo, eu posso apreender uma árvore no horizonte externo que constitui a floresta ou o jardim onde ela está plantada, buscando suas diferenças e sua especificidade, sua contribuição ao efeito estético do todo. Ou eu posso apreendê-la no seu horizonte interno, concentrando-me na textura de sua casca, no arranjo de seus galhos, na forma de sua folhagem para definir sua espécie, seu desenvolvimento, seu estado de saúde ou sua beleza etc. Esses dois horizontes de observação permitem deduzir, de acordo com a perspectiva adotada, propriedades diferentes. A noção de horizonte na qual é encaixado o objeto permite ultrapassar o caráter puramente individual da noção de perspectiva. Pois este modo de se aproximar dos objetos e dos acontecimentos que povoam nosso mundo cotidiano remete aos sistemas de representações transubjetivas que modelam e matizam nossas percepções.

Para ilustrar este fenômeno de atribuição de significado, tomarei o exemplo recente do caso das caricaturas de Maomé, que surgiram na Dinamarca há dois anos. ${ }^{14}$ Esse caso é uma boa ilustração da noção de horizonte e do jogo das representações transubjetivas elaboradas pelos sujeitos e convocadas nas retóricas sociais. A análise de conteúdo dos debates suscitados por esse caso e que ocuparam durantes vários meses o espaço público (imprensa, rádio, TV) mostra que os argumentos dos protagonistas diferiam segundo o horizonte no qual eles se situavam.

Do lado dos que se colocaram contra as caricaturas, distinguem-se referências a:

1) um horizonte religioso que leva a qualificar as caricaturas de blasfêmia - de fato, nas religiões judaica e muçulmana, a imagem de Deus não pode ser objeto de uma representação pictórica. O profeta, encarnação de Deus, não pode ser representado. As caricaturas são uma violação de uma 
proibição sagrada, uma blasfêmia que deve ser condenada como foram os Versos Satânicos de Salman Rushdie.

2) um horizonte comunitário - os muçulmanos formam uma comunidade e todo gesto que afeta um de seus elementos é um atentado à comunidade no seu conjunto. Desenvolvese, então, uma dupla argumentação. A caricatura pode ser vista como uma humilhação. Sendo uma zombaria, ela é interpretada como um insulto dirigido ao conjunto dos muçulmanos que reivindicam seu direito a crer e a defender sua crença. $\mathrm{O}$ insulto é percebido como uma humilhação pelas pessoas, frequentemente ex-colonizados, que se sentem sempre expostas ao desprezo e tomam a caricatura como uma ferida narcísica. E a caricatura pode ser vista como preconceito. Fazendo parecer que todos os muçulmanos pertencem a uma seita islâmica extremista e terrorista, ela se constitui em preconceito contra todos aqueles que se classificam como muçulmanos. O amálgama entre terrorismo e muçulmano é racista e opera em detrimento de toda comunidade que se encontra rejeitada em um mesmo opróbrio.

Do lado dos que defendem as caricaturas, observa-se também uma argumentação fundada sobre dois horizontes de referência. Sob o horizonte da democracia e da Declaração dos Direitos do Homem, de 1948, a caricatura remete a um direito inalienável e universal, assegurando a liberdade de expressão que deve prevalecer sobre a crença religiosa. Sob um horizonte político, aponta-se a história de uma manipulação. Embora condenando o jornal dinamarquês por sua orientação de extrema direita, sublinha-se o atraso da reação por parte dos meios muçulmanos. Denuncia-se, então, na mobilização das massas, uma manipulação islâmica, um controle do político sobre a credulidade das multidões. 


\section{A interação entre as esferas de pertença das representações}

A análise dos debates mostrou não somente a irredutibilidade das posições, mas também o fato de que os horizontes não são necessariamente compatíveis ou cumulativos no interior de uma mesma tomada de posição. Este exemplo mostra que um mesmo objeto ou acontecimento visto por horizontes diferentes dá lugar a negociações de interpretação, confrontos de posição pelos quais os indivíduos exprimem uma identidade e uma pertença. Cada um desses horizontes põe em evidência uma significação central do objeto em função de sistemas de representações transubjetivas específicos dos espaços sociais ou públicos nos quais evoluem os sujeitos. Estes se apropriam dessas representações em função de sua adesão, de sua afiliação a esses espaços.

A esfera da transubjetividade, por ter sido associada a um nível social global ou relacionada a um sistema rígido de determinação, não foi objeto de uma atenção específica no estudo das representações sociais, sendo eliminada das preocupações dos pesquisadores que desejavam respeitar o potencial de criatividade e de liberdade próprio da nova modernidade. Entretanto, como indica o exemplo das caricaturas, não apenas não se pode descuidar de considerá-la, como ela permite afinar a análise do jogo das idéias e das representações. Além disso, como mostra a experiência (Jodelet, 2006), novas perspectivas tentam estabelecer uma ponte entre esta esfera e as outras. Enfim, o encontro entre essas esferas abre um espaço de comunicação e de liberdade, como mostram autores como Arendt e Habermas.

Para Arendt (1983, p. 43), as condições de existência, sejam naturais ou criadas pelos homens, moldam a experiência subjetiva: "a influência da realidade do mundo sobre a existência humana é sentida, recebida como força de condicionamento". Essas condições de existência são a mola do exercício do "pensamento", 
distinto, de acordo com Kant, do "conhecimento", que se refere a um saber positivo. Arendt afirma que nós pensamos a partir de nossa própria experiência e que, pelo viés do pensamento, nossa vida se torna comunicável, partilhável e compreensível para os outros. O pensamento reformula aquilo que nossas condições de existência impõem, e o torna válido para uma comunidade de seres humanos e não somente para uma única pessoa. De tal forma que o pensamento do sujeito, moldado pela esfera transubjetiva, aqui encarnada nos condicionamentos sociais, tornam-se uma voz/via de intersubjetividade. Ao que podemos acrescentar, no que concerne à relação pensamento/conhecimento, o fato de que o pensamento próprio do sujeito é também uma maneira de resistir e de afirmar sua autonomia em relação ao saber e ao conhecimento científico. Uma reflexão de Canguilhem (1978) a respeito do campo médico ilustra isto perfeitamente: “o doente é um Sujeito, capaz de expressão, que se reconhece como Sujeito em tudo aquilo que ele só sabe designar pelos possessivos: sua dor e a representação que ele faz dela, sua angústia, suas esperanças e seus sonhos. [...] É impossível anular na objetividade do saber médico a subjetividade da experiência vivida pelo doente. Esta manifestação da existência merece ser entendida, considerando que ela opõe à racionalidade de um julgamento bem fundado o limite de um tipo de teto impossível de rebentar".

Da mesma forma encontramos em Habermas (1987) um reconhecimento dos constrangimentos que constituem um espaço de transubjetividade, conferindo à intersubjetividade e à linguagem um status de garantia de liberdade:

A infraestrutura linguística da sociedade é um momento de um contexto que, sempre mediado pelos símbolos, constitui-se igualmente por meio dos constrangimentos reais: o de natureza externa, que repercute nos procedimentos do domínio técnico, e o de natureza interna, que se reflete nas repressões que exercem as relações de força social. Estas duas categorias de constrangimentos não são somente objeto de interpretação; à revelia da linguagem, 
elas agem sobre as regras próprias da gramática em função das quais nos interpretamos. (Habermas, 1987, p. 220).

Diante disto, o logos, o pensamento, que toma corpo na linguagem ordinária e na comunicação, permite aos interlocutores guardar a liberdade de exercer, como sujeitos, por meio da expressão de seus entendimentos, um poder que os une.

As reflexões desses autores têm uma pertinência direta para nossa prática de pesquisa sobre representações sociais, no seio das quais nós podemos distinguir o que é do domínio do conhecimento, do saber, do que é do domínio de um pensamento que se desenvolve a partir de nossa experiência concreta. Elas nos convidam a levar em consideração a negociação entre as condições transubjetivas e a libertação que autoriza um pensamento subjetivo comunicável e comunicado na intersubjetividade, bem como a desvendar, no jogo dessas três esferas, as condições de uma liberdade que sustentará as intervenções visando à mudança social. A relação dialética estabelecida entre modos de formação e funções das representações sociais segundo sua atribuição topológica mereceria desenvolvimentos mais amplos, ilustrados por casos empíricos. Eu espero que o quadro que acabou de ser esboçado em traços largos permita que se mensurem as potencialidades da perspectiva subjetivista adotada.

\section{Conclusão}

Ao fim de um percurso, sem dúvida ambicioso, mas necessário, que conclusões tirar? O sujeito aparece sob diferentes figuras: a de uma ilusão ou de uma enganadora transparência; a de uma objetivação em subjetividades historicamente constituídas; a de um poder reflexivo de resistência ou de vigilância; a de uma liberdade que reivindica seus direitos, suas referências identitárias, sua responsabilidade; a de um desafio nos combates simbólicos e políticos. Permitiu-se ver 
a evolução do tratamento da noção de sujeito, os horizontes onde ela é situada, os debates que ela gera, os efeitos que ela ocasiona na prática das ciências humanas e nas proposições de intervenção em vista de uma mudança. Por aí se desenham os contornos de um território de estudo das representações de cada época (Jodelet, 2007a), quer dizer, das representações sociais, coletivas, científicas, estreitamente ligadas ao futuro social e histórico.

Por outro lado, pudemos entrever algumas relações que o sujeito mantém com as representações, produtos e cristalizações de sentido que ele confere a seu universo de vida, ou interiorizações das imposições sociais que o constituem, mediações da expressão de suas identidades. Haveria matéria a desenvolver, assinalando a urgência de reintroduzir esta noção na reflexão psicossociológica sobre o pensamento social.

Falar de sujeito, no campo de estudo das representações sociais, é falar de pensamento, ou seja, referir-se a processos que implicam dimensões físicas e cognitivas, a reflexividade por questionamento e posicionamento diante da experiência, dos conhecimentos e do saber, a abertura para o mundo e os outros. Processos que tomam uma forma concreta em conteúdos representacionais expressos nos atos e nas palavras, nas formas de viver, nos discursos, nas trocas dialógicas, nas afiliações e nos conflitos. Esta especificidade da representação do sujeito como pensamento abre um espaço de pesquisa que ainda precisa ser balizado. Para os autores citados, o termo "sujeito" aparece frequentemente como tendo uma natureza conceitual, abstrata, um caráter programático. Só nos resta dar-lhe carne. O que não será tarefa fácil!

\section{Notas}

1 Para uma apresentação sucinta deste campo de pesquisa, ver Jodelet (2006b). 
2 Nota da tradutora: "sujet-alter-objet", no original francês.

3 Deve-se lembrar que, desde 1970, Moscovici utilizava esta triangulação para superar as dificuldades encontradas pela Psicologia Social na definição de sua unidade de análise e de observação. Para vencer a ótica individualista de pontos de vista taxionômica ou diferencial, ele propunha uma ótica social tomando "como ponto focal a unidade global constituída pela interdependência, real ou simbólica, de vários sujeitos na sua relação com um meio comum, seja este de natureza física ou social. Tal perspectiva é aplicada tanto aos fenômenos de grupo quanto aos processos psicológicos e sociais e incorpora o fato da relação social na descrição e explicação dos fenômenos psicológicos e sociais. Neste caso, a relação Sujeito-objeto é mediada pela intervenção de um outro sujeito, de um "Outro", e torna-se uma relação complexa de sujeito a sujeito e de sujeitos a objetos" (p. 33).

4 Estão incluídas nesta categoria o marxismo, a psicanálise, o estruturalismo.

5 Em 1970, Moscovici declinando daquilo que lhe parecia entrar nos "temas prioritários que constituem o que se pode chamar de objeto de uma ciência”, incluiu, ao lado da ideologia, da comunicação, as relações entre e nos grupos sociais "de que o estudo remete a um problema fundamental da psicologia social: aquele da constituição do 'sujeito social' (indivíduo ou grupo) que recebe na e pela relação existência e identidade sociais" (p. 63).

6 Seria conveniente discutir tanto os recursos quanto os limites que comportam uma referência não somente aos modelos da cognição social mas também àqueles da filosofia do espírito (Fisette, Poirier, 2002). Discussão que ultrapassa o escopo deste artigo.

7 Ver, na sexta Meditação ([1641] 1949, p. 217), a célebre frase: "Eu não estou alojado no meu corpo como um piloto no seu navio, mas estou ligado a ele muito estreitamente, tão confundido e misturado que eu componho um todo com ele".

8 "A idéia cartesiana do corpo humano como humano não fechado, aberto por ser governado pelo pensamento - é talvez a mais profunda idéia da 
união da alma e do corpo. É a alma interferindo em um corpo que não é de si (se fosse, ele seria fechado como um corpo animal), não pode ser corpo e vivo - humano que se completa em uma 'vista de si' que é o pensamento" (Merleau-Ponty, 1964, p. 283).

9 "É unicamente pela ligação da consciência e do corpo em uma unidade natural devida à intuição empírica que é possível algo como uma compreensão mútua entre os seres animados que pertencem a um mesmo mundo. [...] É unicamente por esse meio que cada sujeito de conhecimento pode descobrir o mundo total como algo que o engloba, ele e outros sujeitos, e ao mesmo tempo o reconhece como sendo o único mundo de vida comum a ele e aos outros sujeitos" (Husserl, 1950, p. 179).

10 Nota da tradutora: no texto original, Jodelet utiliza a expressão "prêtà-penser", criando um jogo de palavras que remete a "prêt-à-porter", expressão usada no universo da moda e que se refere às roupas compradas prontas para vestir, em oposição àquelas feitas sob medida.

11 Colocou-se em questão o modelo do longo prazo de Braudel que, durante muito tempo, orientou a escola dos Anais e denunciou uma "reificação" de conceitos como a classe, o território, assim como o privilégio dado aos processos globais.

12 A micro-história emergiu na Itália nos anos 1970, com a escola de Bolonha e autores como Ginzburg e Levi, cujos trabalhos, centrados em personagens singulares, um padre, um moleiro, inscritos em uma história familiar e uma rede de relações sociais, aderiram à necessidade de fazer entender, de dar voz aos atores desconhecidos e de mostrar como os grandes fenômenos como a industrialização, a modernização, a formação do Estado são resultado de estratégias e de trajetórias individuais e familiares. De modo que os fenômenos de agregação e desagregação sociais se encontram reconstruídos do ponto de vista das condutas e identidades individuais.

13 Note-se que, mesmo na antropologia, diversas interpretações desta oposição foram propostas desde Evans-Prichard, que a entende como decorrente de um processo de diferenciação social onde o "não-nós" 
é necessário à afirmação identitária de um "nós", até Héritier, que baseia a formação binária das categorias de pensamento na experiência originária e primordial do corpo sexuado.

14 Vou recordar rapidamente esse episódio e seus desdobramentos. Um jornal dinamarquês de extrema direita publicou uma série de caricaturas do profeta Maomé das quais uma em particular (uma cabeça do profeta barbudo cujo turbante branco servia de ninho a uma pomba), desencadeou, quatro meses mais tarde, em vários meios e países islâmicos, um movimento de protesto com amplitude e violência raras (manifestações de rua, ataque às embaixadas dinamarquesas, cremação de efígies e bandeiras etc.). Esse movimento ocasionou diversas reações de reprovação e, no contexto democrático francês, uma defesa da imprensa. Assim, a publicação semanal Charlie-Hebdo reproduziu as caricaturas em gesto de solidariedade e afirmação da liberdade de imprensa. Essa publicação gerou acalorados debates públicos e tomadas de posição contraditórias. O veículo, que foi citado em justiça por um órgão oficial de representação da comunidade muçulmana, recebeu apoio de diversas personalidades do mundo científico, jurídico e político. O julgamento indeferiu as queixas.

The return to the notion of subject and the approach of social representations

\begin{abstract}
The article notes a return, in social sciences, to the notion of subject likely to lead to a new approach of subjectivity in the field of study of social representations. After an examination of the moments that have signified the death and resurrection of the notion of subject, it develops the different themes characterizing the reintegration of this notion in history, sociology and anthropology. These themes allow to rule out the risk of a solipsist vision in the treatment of the subjective part of social representations. For that purpose, a schema is proposed, relating the genesis and the functions of social representations to three spheres (subjective, inter-subjective, trans-subjective), and illustrated by an analysis of the debates concerning the famous Mahomet's caricatures affair.
\end{abstract}


The final remarks claim to orient the study of social representations towards the relations between thinking and social change.

Keywords: social representations; subject; subjectivity; intersubjectivity; trans-subjectivity; horizon; thinking.

\section{Referências bibliográficas}

ABRIC, J.C. Pratiques sociales et représentations. Paris: PUF, 1994.

ARENDT, H. La condition de l'homme moderne, Paris: Calmann-Lévy, 1983.

BALIBAR, É.; CASIN, B.; LIBERA, L. de. Entrée "sujet”. In: CASSIN, B. (sous la direction de). Vocabulaire européen des philosophies. Paris: Le Seuil, Le Robert, 2004.

BOUDON, R. Sens et raisons: théorie de l'argumentation et sciences humaines. Hermes, n. 16, p. 29-43, 1995.

BOUREAU, A. Proposition pour une histoire restreinte des mentalités. Annales ESC, n. 6, p. 1491-1504, 1989.

BUTLER, J. The psychic life of power: theories in subjection. Berkeley: Stanford University Press, 1995. [Trad. française: La vie psychique du pouvoir: l'assujettissement en théories. Paris, Éditions Leo Scheer, 2002].

CANGUILHEM, G. Une pédagogie de la guérison est-elle possible? Nouvelle Revue de Psychanalyse, n. 17, p. 13-26, 1978.

. Le cerveau et la pensée. In: COLLOQUE GEORGES CANGUILHEM: PHILOSOPHE HISTORIEN DES SCIENCES. Actes $d u \ldots$ Paris: Bibliothèque du Collège Iinternational de Philosophie, Albin Michel, 1993.

CHARTIER, R. Le monde comme représentation. Annales ESC, n. 6, p. 1505-1520, 1989.

CHOMSKY, N. Langage et pensée: quelques réflexions sur des thèmes vénérables. In: CHOMSKY, N; FOUCAULT, M. Sur la nature 
humaine: comprendre le pouvoir. Bruxelles: Aden, 2006. p. 87148.

DELEUZE, G.; GUATTARI, F. Mille plateaux. Paris: Éditions de Minuit, 1980.

DESCARTES. R. Les méditations. Paris: Gallimard, [1641] 1949. (Coll. La Pléiade).

DESCOLA, P. Par-delà nature et culture. Paris: Gallimard, 2006.

DOSSE, F. L'empire du sens: l'humanisation des sciences humaines. Paris: La Découverte, 1995.

DOISE, W. Les représentations sociales. In: GHIGLIONE, R.; BONNET, C.; RICHARD, J .F. (sous la direction de). Traité de psychologie cognitive 3: cognition, représentation, communication. Paris: Dunod, 1990. p. 111-174.

DURKHEIM, É. Représentation collective et représentation individuelle, In: . Sociologie et philosophie. Paris: PUF: 1895.

FISETTE, D.; POIRIER, P. Philosophie de l'esprit: Psychologie du sens commun et sciences de l'esprit. Paris: Vrin, 2002.

FOUCAULT, M. L’herméneutique du sujet: cours au Collège de France, 1981-1982. Paris: Gallimard, Le Seuil, $2001 a$.

. Dits et écrits II, 1976-1988. Paris: Gallimard, Quarto, 2001b.

GERGEN, K. J. The saturated Self: dilemnas of identity in contemporary life. New York: Basic Books, 1991.

GIDDENS, A. Profiles and critiques in Social Theory, In: CASSELL, P. (sous la direction de). The Giddens Reader. Londres: Macmillan Press, [1982] 1993.

GODELIER, M. Au fondement des sociétés humaines: ce que nous apprend l'Anthropologie. Paris: Albin Michel, 2007.

GUATTARI, F. De la production de subjectivité. Revue Chimères, n. 4, p. 1-19, 1986. 
HABERMAS, J. La logique des sciences sociales. Paris: PUF, 1987.

JACQUES, F. Écrits anthropologiques: Philosophie de l'esprit et cognition. Paris, L'Harmattan, 2000.

JODELET, D. Représentations sociales : un domaine en expansion. JODELET, D.(sous la direction de). Les représentations sociales. 7e éd. Paris: PUF, [1989] 2003.

. Formes et figures de l'altérité. In: SANCHEZ-MAZAS, M; LICATA, L. (sous la direction de) L'autre. Regards psychosociaux. Grenoble: PUG, 2005. p. 23-47.

. Place de l'expérience vécue dans les processus de formation des représentations socials. In: HAAS, V. (sous la direction de). Les savoirs du quotidian. Rennes: PUR, 2006a. p. 235-255.

. Représentation sociale. In: MENSURE, S.; SAVIDAN, P. (sous la direction de), Le dictionnaire des sciences humaines. Paris: PUF, 2006b. p. 1003-1005,

. Imaginaires érotiques de l'hygiène féminine intime: approche anthropologique. Connexions 87, p. 105-128, 2007 a.

. Imbricações entre representações sociais e intervenção. In: MOREIRA, S. P.; CAMARGO, B. V. (Orgs.). Contribuições para a teoria e o método de estudo das representações sociais. João Pessoa, UFPB, 2007b. p. 45-73.

KAES, R. L'appareil psychique group: construction du groupe. Paris: Dund, 1976.

LEPETIT, B. Les formes de l'expérience: une autre histoire sociale. Paris: Albin Michel, 1995.

MARKOVA, I. Dialogicité et représentations sociales: la dynamique de l'esprit. Paris: PUF, 2007.

MERLEAU-PONTY, M. Le visible et l'invisible. Paris: Gallimard, [1964] 2004.

. L'institution: la passivité. Notes de cours au Collège de France. Paris: Belin, 2003. 
MILON, A. Descartes. In: Marzano, M. Dictionnaire du corps. Paris: PUF, 2007. p. 292-296.

MOSCOVICI, S. Préface. In: JODELET, D.; VIET, J.: BESNARD, P. La psychologie sociale: une discipline en movement. Paris-La Haye: Mouton, 1970. p. 9-64. . La psychanalyse, son image et son public. Paris: PUF, [1961] 1976.

. Le domaine de la psychologie sociale. In: MOSCOVICI, S. La psychologie sociale. Paris: PUF, 1984.

. Social representations: explorations in Social Psychology. Cambridge: Polity Press, 2000.

NOIRIEL, G. Pour une approche subjectiviste du social. Annales ESC, n. 6, p. 1435-1459, 1989.

RIOUX, J. P.; SIRINELLI, J. F. Pour une histoire culturelle. Paris: Le Seuil, 1997.

SEARLE, J. Les actes de langage. Paris: Hermann, 1979.

TOURAINE, A. Penser autrement. Paris: Fayard, 2007.

ZAVALLONI, M. Ego-écologie et identité: une approche naturaliste. Paris: PUF, 2007.

ZIZEK, S. Le sujet qui fâche: le centre absent de l'ontologie politique. Paris: Flammarion, 1999. 